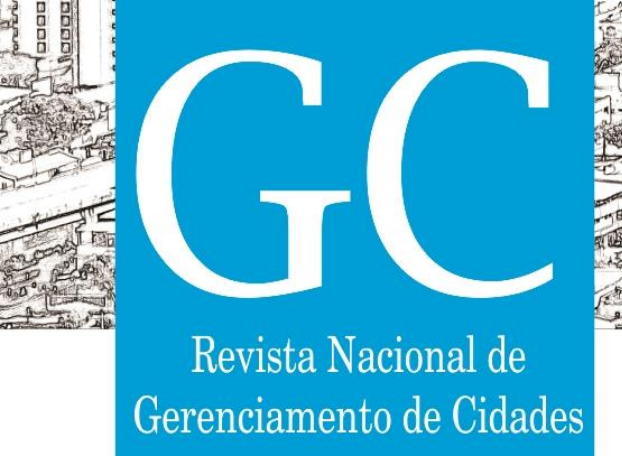

ISSN 2318-8472

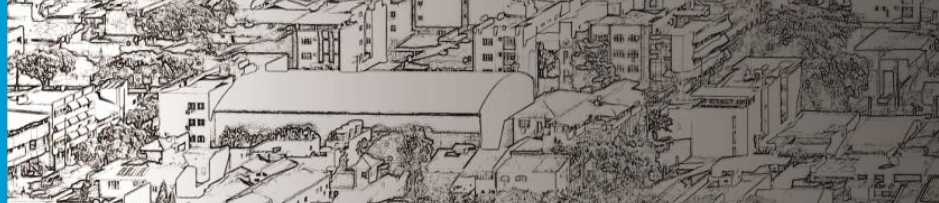

v. 08, n. 57,2020

\title{
Elementos estruturadores do território e os efeitos na borda urbana de Passo Fundo/RS
}

Structuring elements of the territory and the effects on the urban border of Passo Fundo / RS

Elementos estructurantes del territorio y los efectos en la frontera urbana de Passo Fundo / RS

Laércio Stolfo Maculan Arquiteto e urbanista FAURB/UFPEL; Mestre em Engenharia e Meio Ambiente PPENG/UPF; Doutorando em Arquitetura no PROARQ/UFRJ; Professor da Escola de Arquitetura e Urbanismo - IMED laercio.maculan@imed.edu.br

\section{Vera Regina Tângari}

Graduação em Arquitetura e Urbanismo. Instituto Metodista Bennett; Mestrado em Urban Planning. University of Michigan; Doutorado em Arquitetura e Urbanismo. Universidade de São Paulo, USP; Pós-Doutorado. Pontifícia Universidade Católica de Campinas, PUC. Universidade Federal do Rio de Janeiro, Reitoria, Centro de Letras e Artes.

- Rio de Janeiro, RJ - Brasil vtangari@gmail.com. 


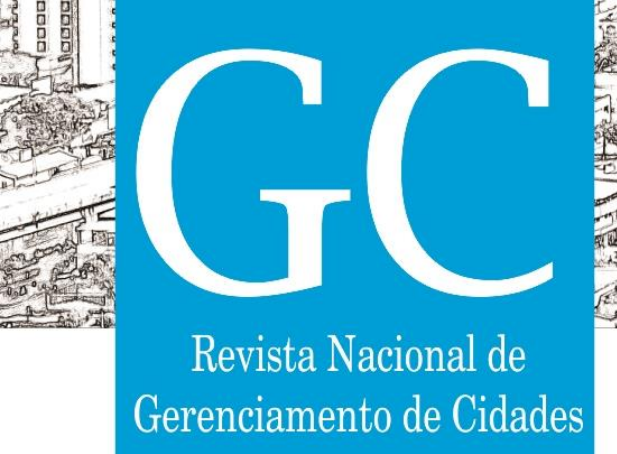

\section{RESUMO}

Este trabalho tem como objetivo discutir os efeitos dos elementos que estruturam a ocupação do território na borda de uma cidade de porte médio no Sul do Brasil, no período de 2000 e 2018. Os elementos como o suporte geofísico, a Região Metropolitana de Porto Alegre (RMPA), os corredores de desenvolvimento e as aglomerações urbanoindustriais são importantes, pois influenciam no desenvolvimento das localidades e estruturam as dinâmicas regionais. O objeto de interesse é o município de Passo Fundo/RS, enquanto cidade-polo da região do Conselho Regional de Desenvolvimento Produção. Esta região se caracteriza, na economia e na paisagem, por estar inserida no espaço predominantemente voltado ao agronegócio globalizado. Como resultado, foi possível observar que os elementos estruturadores, como a RMPA, influenciam na ocorrência de vetores de crescimento. As rodovias regionais concentram os estabelecimentos de empresas. Na borda, estão localizadas as atividades industriais e comerciais e as áreas de agricultura urbana voltada à matriz do agronegócio globalizado. Os fenômenos observados são complexos, e de maneira nenhuma se buscam simplificações, uma vez que, ao discutir as transformações fomentadas, seja por características locais e elementos regionais ou pelo agronegócio, este artigo busca colaborar com os planejadores na tomada de decisão com uma visão geral dos efeitos que estas estruturas podem causar na borda de uma cidade média inserida no contexto do agronegócio.

PALAVRAS-CHAVE: elementos estruturadores; matriz do agronegócio; borda urbana; cidade média.

\section{ABSTRACT:}

This paper aims to discuss the effects of the elements that structure the occupation of the territory on the edge of a medium-sized city in southern Brazil, between 2000 and 2018. Elements such as geophysical support, the Porto Alegre Metropolitan Region (RMPA), development corridors and urban-industrial agglomerations are important as they influence the development of localities and structure regional dynamics. The object of interest is the municipality of Passo Fundo / RS, as a hub city in the region of the Regional Council for Production Development. This region is characterized, in the economy and landscape, by being inserted in the space predominantly focused on globalized agribusiness. As a result, it was possible to observe that the structuring elements, such as the RMPA, influence the occurrence of growth vectors. Regional highways concentrate business establishments. On the border are located the industrial and commercial activities and the areas of urban agriculture focused on the globalized agribusiness matrix. The observed phenomena are complex, and by no means seek simplifications, since in discussing the transformations fostered, either by local characteristics and regional elements or by agribusiness, this article seeks to collaborate with decision-makers on an overview. of the effects that these structures can have on the edge of an average city inserted in the context of agribusiness.

KEYWORDS: Structural elements; agribusiness matrix; urban border; Average city.

\section{RESUMEN}

Este documento tiene como objetivo discutir los efectos de los elementos que estructuran la ocupación del territorio en el borde de una ciudad mediana en el sur de Brasil, entre 2000 y 2018. Elementos como el apoyo geofísico, la Región Metropolitana de Porto Alegre ( RMPA), los corredores de desarrollo y las aglomeraciones urbano-industriales son importantes ya que influyen en el desarrollo de localidades y estructuran la dinámica regional. El objeto de interés es el municipio de Passo Fundo / RS, como ciudad central en la región del Consejo Regional para el Desarrollo de la Producción. Esta región se caracteriza, en la economía y el paisaje, por estar insertada en el espacio predominantemente enfocado en los agronegocios globalizados. Como resultado, fue posible observar que los elementos estructurantes, como el RMPA, influyen en la aparición de vectores de crecimiento. Las carreteras regionales concentran establecimientos comerciales. En la frontera se encuentran las actividades industriales $y$ comerciales y las áreas de agricultura urbana centradas en la matriz de agronegocios globalizada. Los fenómenos observados son complejos y de ninguna manera buscan simplificaciones, ya que al analizar las transformaciones fomentadas, ya sea por características locales y elementos regionales o por agronegocios, este artículo busca colaborar con los tomadores de decisiones en una visión general. de los efectos que estas estructuras pueden tener en el borde de una ciudad promedio insertada en el contexto de los agronegocios.

PALABRAS CLAVE: elementos estructurantes; matriz de agronegocios; borde urbano; Ciudad media. 


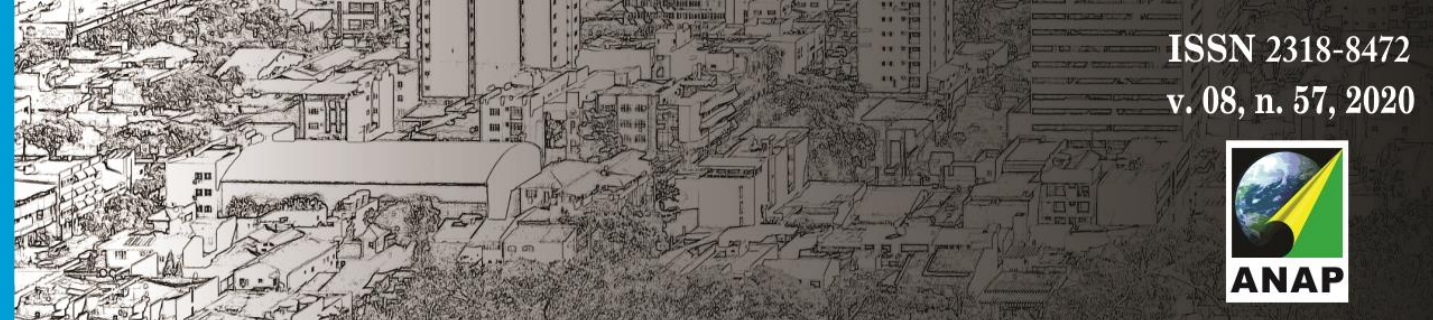

Revista Nacional de

Gerenciamento de Cidades

\section{INTRODUÇÃO}

O processo da urbanização brasileira teve início e concentrou-se ao longo da região costeira. Um momento importante no processo de ocupação do território, segundo Santos (1993), ocorreu entre as décadas de 1940 e 1980, quando houve uma verdadeira inversão quanto ao lugar de residência da população brasileira: a taxa de urbanização passou de $26,35 \%$ para $68,86 \%$. Neste período ocorreram de forma simultânea dois processos de metropolização e desmetropolização, com a polarização das aglomerações urbano-industriais e o crescimento das cidades grandes (principalmente as metrópoles) e das cidades médias. A cidade de São Paulo representa até os dias de hoje a polarização mais intensa, muito devido à importância industrial, mas principalmente por produzir, coletar e classificar informações próprias e de outros, perfazendo dela a capital onipresente do território brasileiro.

A parte do Brasil que é agrícola mantém seus processos graças à estrutura e às relações estabelecidas com a cidade, pois esta abriga as atividades e os serviços necessários para o ciclo produtivo. As cidades médias $^{1}$ se configuram como importantes polos que dão suporte à produção agrícola, atuando decisivamente no processo produtivo com insumos e assessoramentos técnico e tecnológico, além de ter papel importante na colheita, no armazenamento e no escoamento da produção. A cidade de Passo Fundo é a principal cidade do norte do estado do Rio Grande do Sul, além de ser uma das precursoras no cultivo de precisão de monocultura de grãos (trigo, soja e milho).

A interface entre o tecido urbano, a zona rural e de cultivo e, os elementos estruturadores ocorre na borda urbana. Por isso o estudo da borda urbana requer o esforço combinado de estudiosos em diferentes disciplinas, de modo a desenhar uma conjuntura coerente da variedade de forças, condições e influências que moldam a cidade contemporânea. As bordas são essenciais para as pessoas que estão presentes dentro e ao longo delas, pois são entidades multidimensionais e transescalares que têm o potencial de contribuir para a amplificação ou a eliminação da diferença sociomaterial na cidade (IOSSIFOVA, 2013).

Este artigo busca discutir de que maneira os elementos estruturadores da Região Sul do Brasil contribuem para definição da borda urbana de Passo Fundo. Portanto, por meio da sistematização e da descrição dos mais significativos elementos observados, procura-se responder a seguinte pergunta: de que maneira os elementos estruturadores influenciaram a formação da borda urbana de Passo Fundo/RS no período de 2000 a 2018? Para responder à questão, foram elencados os elementos que estruturam o território, e, para cada um dos

\footnotetext{
${ }^{1}$ Para Santos (2010), são as cidades que não são capitais estaduais, têm mais de 100 mil habitantes e estão se tornando centros regionais de serviços.

Segundo Amorim Filho e Serra (2001), não há uma ideia consensual do que seriam as cidades médias, uma classificação indistinta que categorize. O critério demográfico apenas identifica o grupo ou a faixa que pode conter cidades médias. Esse critério tem sido o mais utilizado pela complexidade de relacionar atributos que apresentam grande variabilidade, como relações externas, estrutura interna e problemas sociais das cidades médias.
} 


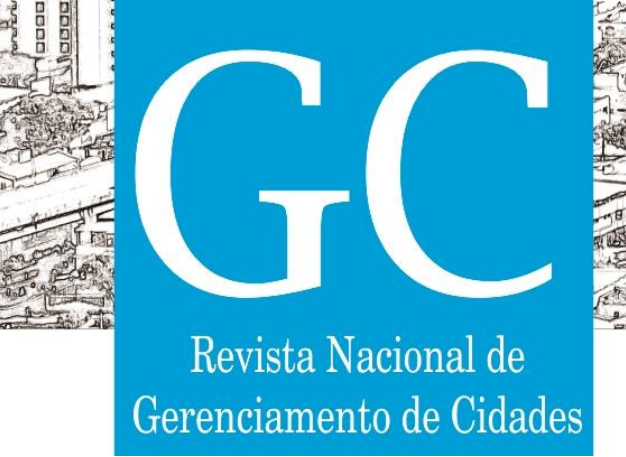

Um dos efeitos das regiões produtoras do agronegócio globalizado são os círculos de cooperação e os circuitos espaciais da produção de importantes commodities que são predominantes sobre os demais, cada vez menos resistentes às ingerências exógenas e aos novos signos do período histórico atual, comandado por algumas empresas hegemônicas do setor (ELIAS, 2015).

\section{A MATRIZ DO AGRONEGÓCIO GLOBALIZADO: O CONTEXTO DE PASSO FUNDO}

Para compreender os efeitos da matriz do agronegócio globalizado na formação da borda urbana de Passo Fundo, foi proposto um recorte espacial político-administrativo: foram analisados o Corede ${ }^{4}$ Produção e os municípios que o compõem. O Corede Produção é composto por 21 municípios, que podem ser observados na Figura 2. A região conta com 338.049 habitantes; os municípios de Passo Fundo (184.826 hab.), Carazinho (59.317 hab.) e Marau (36.364 hab.) concentram $82 \%$ do total de habitantes, os demais municípios apresentam uma média de 3.200 habitantes (IBGE, 2010).

Quanto à taxa de urbanização, a do Rio Grande do Sul é de $85,1 \%$, e a do Corede Produção é de $87,9 \%$. As cidades de Passo Fundo (97,5\%), Carazinho (98,2\%) e Marau (86,8\%) são urbanizadas acima da média, as demais cidades do Corede Produção apresentam taxa média de $48,1 \%$. Os dados populacionais podem ser relacionados à procura ou à disponibilidade de emprego, pela tendência de redução do número de habitantes nas cidades pequenas e de aumento na cidade de Passo Fundo devido ao efeito da polarização.

\footnotetext{
${ }^{4}$ O Rio Grande do Sul foi dividido em 28 unidades que constituem os Conselhos Regionais de Desenvolvimento (Coredes). Segundo lei estadual de 1994, o conselho permite a participação da sociedade civil no debate do desenvolvimento regional (FINAMORE, 2010).
} 


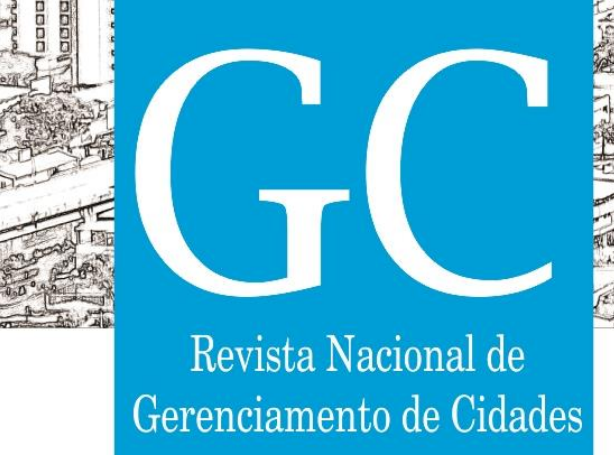

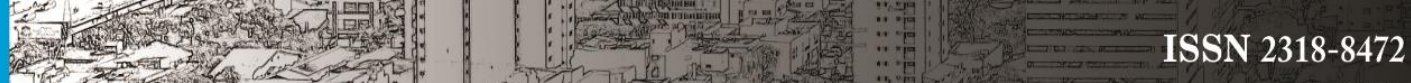

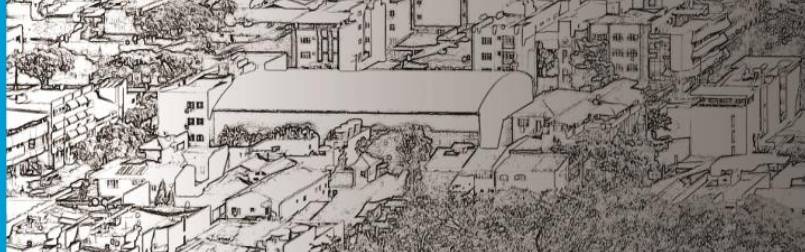

v. 08, n. 57,2020

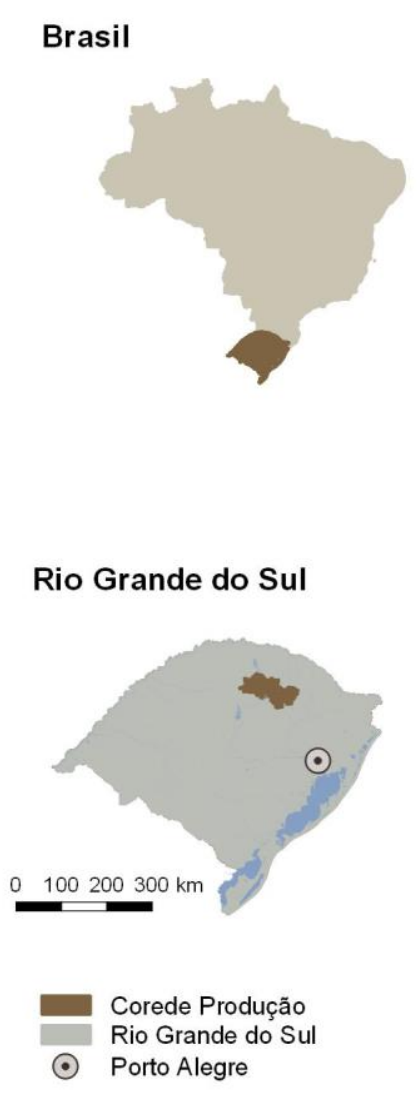

Rio Grande do Sul

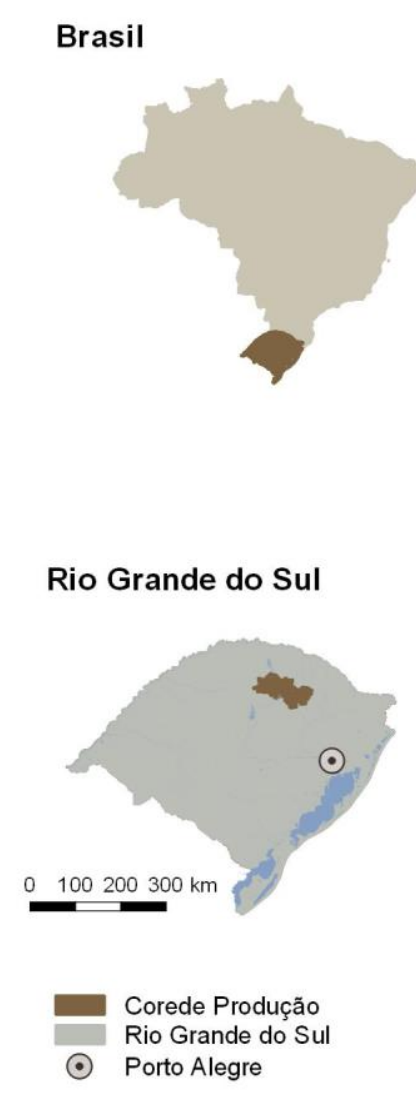

Corede Produção

Rio Grande do Sul

-) Porto Alegre

Figura 2: Contexto do Corede Produção

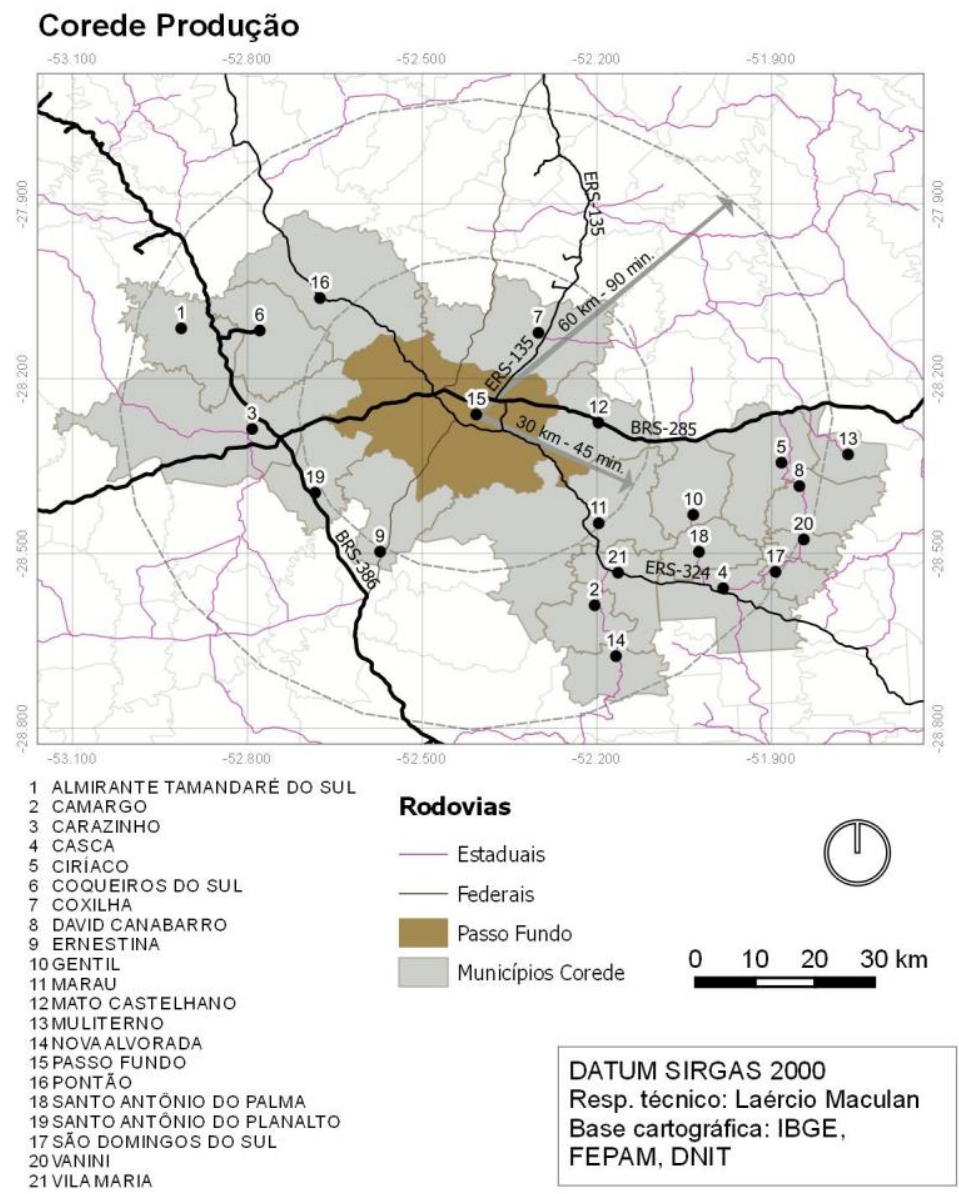

Fonte: autor, 2019.

A taxa de crescimento populacional entre os anos 2000 e 2010 no Brasil foi de 11,5\%; no Rio Grande do Sul, de 4,7\%; e no Corede Produção, de 6,7\%. As cidades que apresentaram maiores índices de crescimento foram Marau (22\%), Nova Alvorada $(13,4 \%)$ e Passo Fundo $(8,9 \%)$; dezoito municípios apesentaram crescimento abaixo da média do Rio Grande do Sul (4,7\%); e doze apresentaram decréscimo. Este fenômeno pode ser explicado pela diminuição da taxa de natalidade que vem ocorrendo no Estado e, principalmente, pelo processo de migração para outras localidades em busca de emprego e renda.

Para analisar os aspectos econômicos a porcentagem de pobres e o Índice de Gini. Quanto ao percentual de pobres ${ }^{5}$, o Brasil em 2000 tinha 27,9\% das pessoas nesta condição; em 2010, o índice diminuiu para 15,1\% O Rio Grande do Sul, em 2000, tinha 15,5\% das pessoas em condição

\footnotetext{
${ }^{5} \mathrm{O}$ percentual de pobres se refere à proporção dos indivíduos com renda domiciliar per capita igual ou inferior a 140 reais mensais em agosto de 2010. O universo de indivíduos é limitado àqueles que vivem em domicílios particulares permanentes.
} 


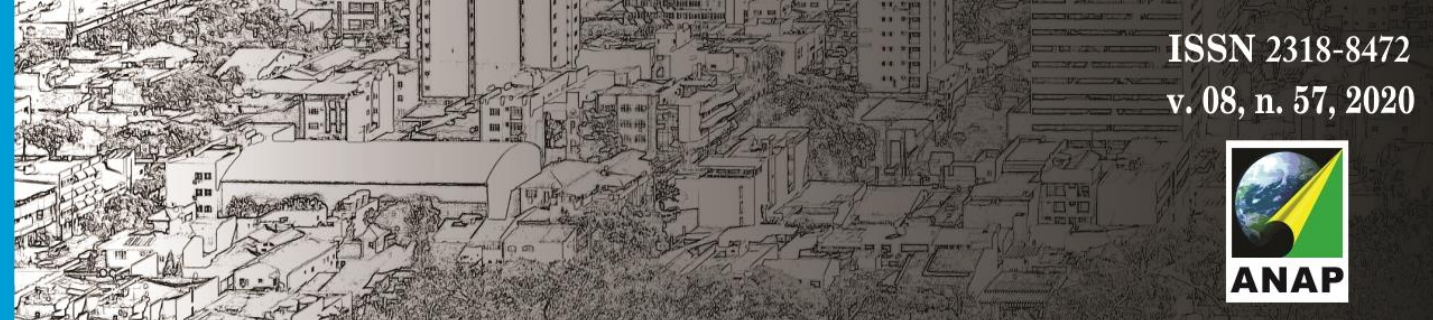

\section{Revista Nacional de}

Gerenciamento de Cidades

de pobreza; em 2010, contava com 6,3\%. O Corede Produção tinha $15,7 \%$ de taxa de pobreza em 2000; em 2010, passou para 5,25\%. Quanto ao Índice de Gini ${ }^{6}$, o Brasil em 2010 apresentou 0,60 de índice; o Rio Grande do Sul, 0,55; e o Corede Produção, 0,47. As cidades com o maior índice de desigualdade foram Passo Fundo $(0,53)$, Coqueiros do Sul $(0,54)$ e Mato Castelhano $(0,56)$, onde há alta concentração de renda. As menores desigualdades foram registradas em Vanini $(0,35)$, Camargo $(0,39)$ e Vila Maria $(0,41)$. Espacialmente é possível observar que há relação entre a localização espacial e a desigualdade, pois as cidades localizadas nas áreas em que há maiores extensões de cultivo voltadas ao agronegócio globalizado foram as que tiveram índices de desigualdade maiores.

Figura 3: Percentual do emprego por setor

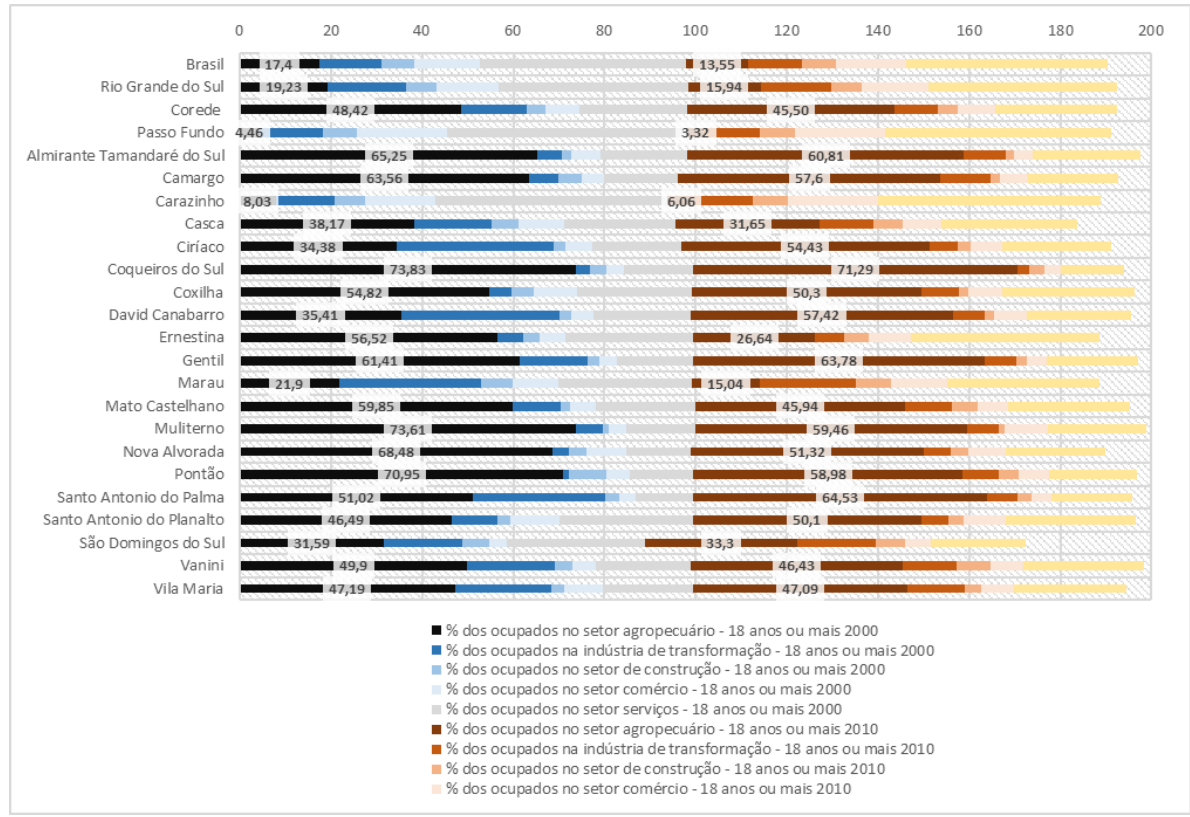

Fonte: autor, 2019.

O emprego é uma variável importante foi avaliado a questão da ocupação dos trabalhadores ${ }^{7}$, conforme a Figura 3, a região apresenta nos setores de ocupação alto índice de trabalhadores no setor agropecuário. No contexto brasileiro, em 2000, este índice era de 17,4\% e, em 2010, de 13,5\%. No Rio Grande do Sul, em 2000, 19,23\% dos trabalhadores atuavam no setor agropecuário e, em 2010, 15,94\%. O Corede Produção apresentava, em 2000, percentual de $48,4 \%$ de ocupados com 18 anos ou mais de idade no setor agropecuário e, em 2010, 45,9\%. Os

\footnotetext{
${ }^{6} \mathrm{O}$ Índice Gini mede o grau de desigualdade existente na distribuição de indivíduos, segundo a renda domiciliar per capita. $O$ índice varia de 0 , quando não há desigualdade (a renda domiciliar per capita de todos os indivíduos tem o mesmo valor), a 1, quando a desigualdade é máxima (apenas um indivíduo detém toda a renda). $O$ universo de indivíduos é limitado àqueles que vivem em domicílios particulares permanentes.

${ }^{7}$ Foram considerados os trabalhadores com 18 anos ou mais de idade.
} 


\section{Revista Nacional de}

Gerenciamento de Cidades

nacional ou com desempenho próximo são Passo Fundo (17,66\%), Carazinho (13,87\%), Casca $(13,03 \%)$ e Marau (12,01\%). As demais cidades do Corede Produção têm menos de $9 \%$ de ocupados com ensino superior.

$\mathrm{Na}$ análise dos três aspectos e pela comparação com a espacialização das observações, foi possível perceber que os resultados econômicos (porcentagem de pobres e Índice de Gini), o trabalho (ocupação dos trabalhadores) e o capital humano (grau de escolaridade dos ocupados) são influenciados pela localização das cidades. Os municípios localizados em áreas onde as manchas de cultivo são de grão grosso, e, assim sendo, o agronegócio é mais intenso apresentam taxas e índices piores em relação aos municípios que estão em zonas onde as manchas de cultivo são de grão médio A comparar as séries históricas do IBGE para os anos de 2000 e 2010, foi possível observar que a região apresentou evolução em todas as análises.

\section{OS EFEITOS DOS ELEMENTOS ESTRUTURADORES E DA MATRIZ DO AGRONEGÓCIO NA BORDA URBANA}

Esta etapa da análise visa a compreender os efeitos dos elementos estruturadores e da matriz do agronegócio na escala da borda urbana de Passo Fundo. A cidade-polo reconhece as tensões e se aproveita destes fluxos e vetores de crescimento, assumindo localizações futuras e desenvolvendo nestas direções.

Para melhor compreender os fenômenos e efeitos dos elementos estruturadores nas bordas urbanas, foi proposto um detalhamento em quatro quadrantes na escala 1/50.000. No quadrante da borda a nordeste, conforme a Figura 5, é possível observar os processos morfológicos relacionados aos elementos estruturadores, em que o tecido é seccionado (1) pela ERS-135 e pela BR-285, esta rodovia federal foi duplicada, e a seç̧ão é mais contundente neste local. Outro fato observado é a locação de famílias destinada à habitação de interesse social (2) distante do centro urbano consolidado, por consequência demandam elevados custos em deslocamento e incrementando a segregação urbana. 


\section{Revista Nacional de}

Gerenciamento de Cidades

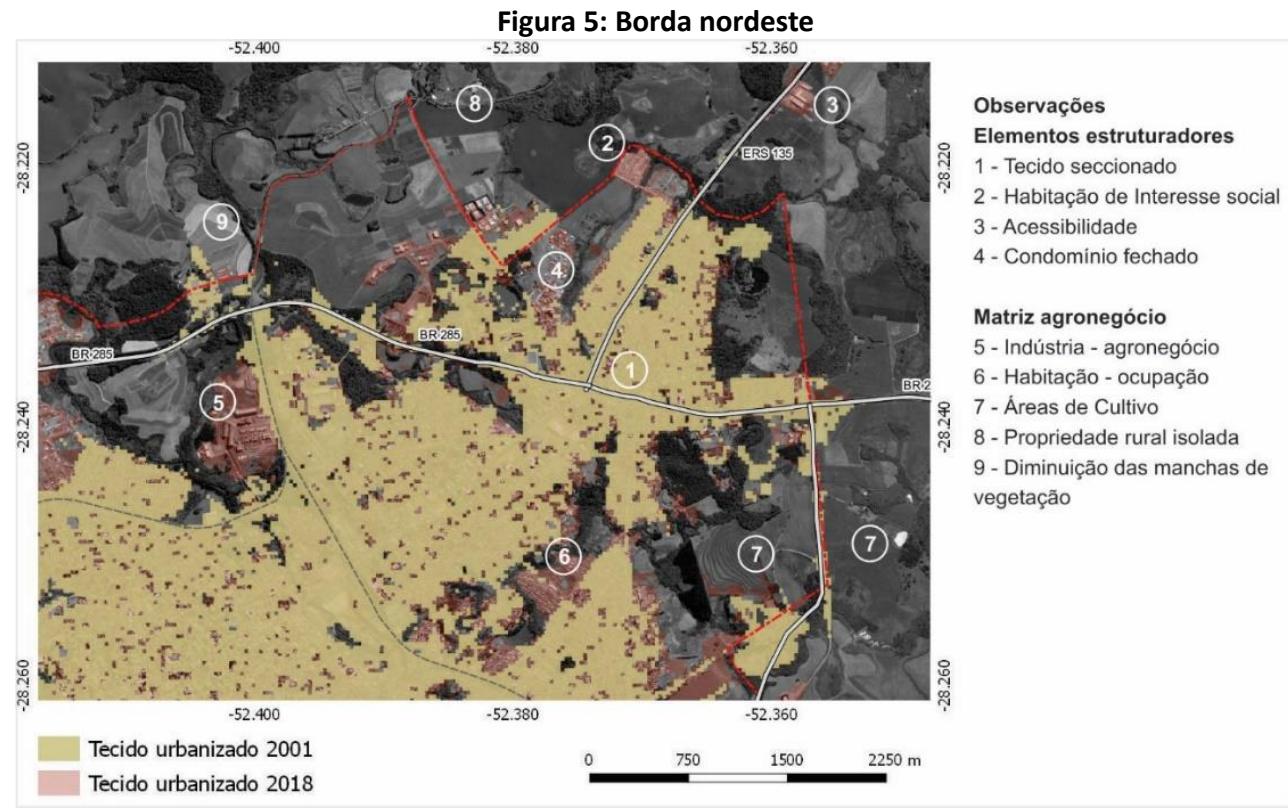

Fonte: autor, 2019.

Outro fato é a localização de empresas (3) ao longo das rodovias para usufruir da localização e da acessibilidade que a via proporciona (VILLAÇA, 2001). Neste setor, foi implantado um condomínio fechado (4); estas habitações, segundo Otero (2016), promovem novas territorialidades e alteram a lógica locacional dos estratos de mais alta renda, pois não ocupam mais o centro bem equipado, mas as franjas da cidade, e, assim, demandam a mobilidade individual do automóvel.

Quanto à matriz do agronegócio, neste quadrante está localizada a empresa de beneficiamento de biodiesel a base de soja (5). Estão localizadas ainda a Universidade de Passo Fundo e a Empresa Brasileira de Pesquisa Agropecuária - Trigo, que auxiliam há décadas no processo que Milton Santos (1993) chamou de meio técnico-científico, voltado para difusão e interiorização de tecnologias no campo. As áreas de cultivo (7) são manchas de grão grande, e as edificações rurais (8) encontram-se esparsas e isoladas, o que demonstra o perfil desta zona de produção alinhado às premissas da matriz do agronegócio globalizado.

O quadrante da borda noroeste, conforme observado na Figura 6, apresenta as seguintes relações com os elementos estruturadores: uso e ocupação do solo de forma monofuncional (1) como efeito principal, pois trata-se da zona industrial prevista no Plano Diretor, baixa atratividade, desagregação e muitos vazios urbanos. Outro fator observado é a implantação do bairro José Alexandre Zachia (2), o qual foi fundado na década de 1980, devido à implementação de um condomínio de habitação social, para o qual foram selecionados moradores de várias localidades e onde foram socioespacialmente segregados. Atualmente o bairro tem se expandido espontaneamente em função da ocorrência de assentamentos precários (3) que estão se desenvolvendo em seu entorno. Segundo Silveira (2014), a formação da borda é 


\section{Revista Nacional de}

Gerenciamento de Cidades

caracterizada por processos que resultam em baixas densidades construtiva e populacional e dificuldades de mobilidade devido às condições de deslocamento cotidiano, à segregação social, à dispersão da cidade e à expansão urbana para fora.

\section{Figura 6: Borda noroeste}

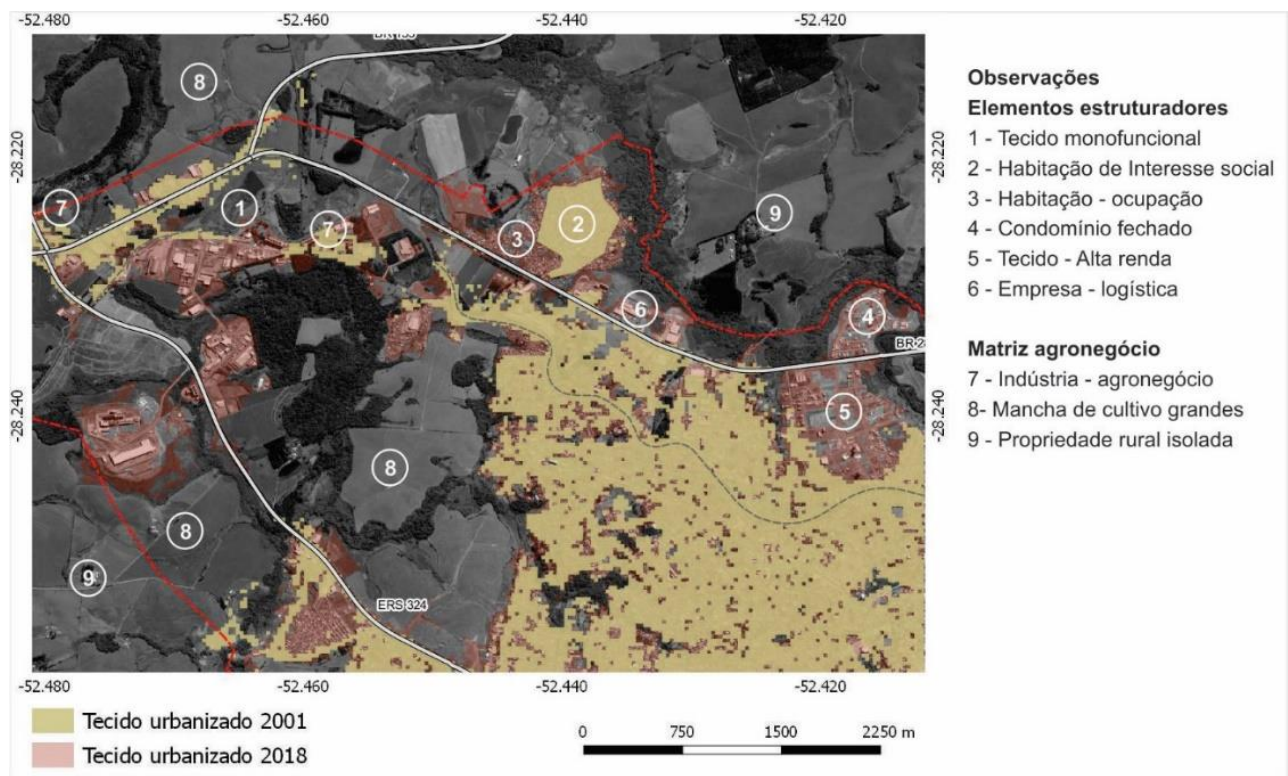

Fonte: autor, 2019.

É observado um vetor de ocupação das camadas de alta renda do centro em direção à borda (VILLAÇA, 2001), este é formado pelo condomínio fechado (4) e pela consolidação de um vazio urbano (5). Ao longo da BR-285 estão localizados empresas, indústrias e centros comerciais, principalmente voltados à logística (6), pois esta rodovia é a principal ligação com o corredor de desenvolvimento BR-116.

Quanto à matriz do agronegócio, este quadrante contém o distrito industrial e, ao longo das rodovias, os equipamentos destinados ao recebimento e ao armazenamento de grãos (7). As manchas de cultivo são de grão grande (8) e estão localizadas dentro do perímetro urbano. As edificações rurais (9) são esparsas e isoladas no território.

A borda do quadrante sudeste pode ser analisada na Figura 7; as relações entre os elementos estruturadores e o espaço urbano são adição de tecidos (1) no vazio entre a cidade consolidada e a via Perimetral Leste, e o resultado da forma urbana é o tecido fragmentado. As empresas de logística e distribuição (2) configuram uma tipologia pavilhonar ao longo da Via Perimetral. Foram implementados condomínios fechados (3) ao longo da ERS-324. Esta via assume o papel de via arterial (4), pois tem a função de conexão entre os bairros que se localizam ao longo dela; segundo Flávio Villaça (2001), as vias regionais, à medida que as cidades crescem, mudam de função e passam a ser vias de tráfego intra-urbano. 
A paisagem desta borda se caracteriza pela presença da matriz do agronegócio, porém em menor intensidade, se comparado aos quadrantes nordeste e noroeste. $\mathrm{O}$ suporte físico nesta área apesenta recursos hídricos e declividades elevadas, o que acarreta manchas de cultivo menores (6) ou, por vezes, impede o cultivo de grãos (soja e milho); assim sendo, há permanência de mancha de vegetação nativa (8). Outro fator é a presença de propriedades de pequenos agricultores e de chácaras ao longo dos recursos hídricos (6).

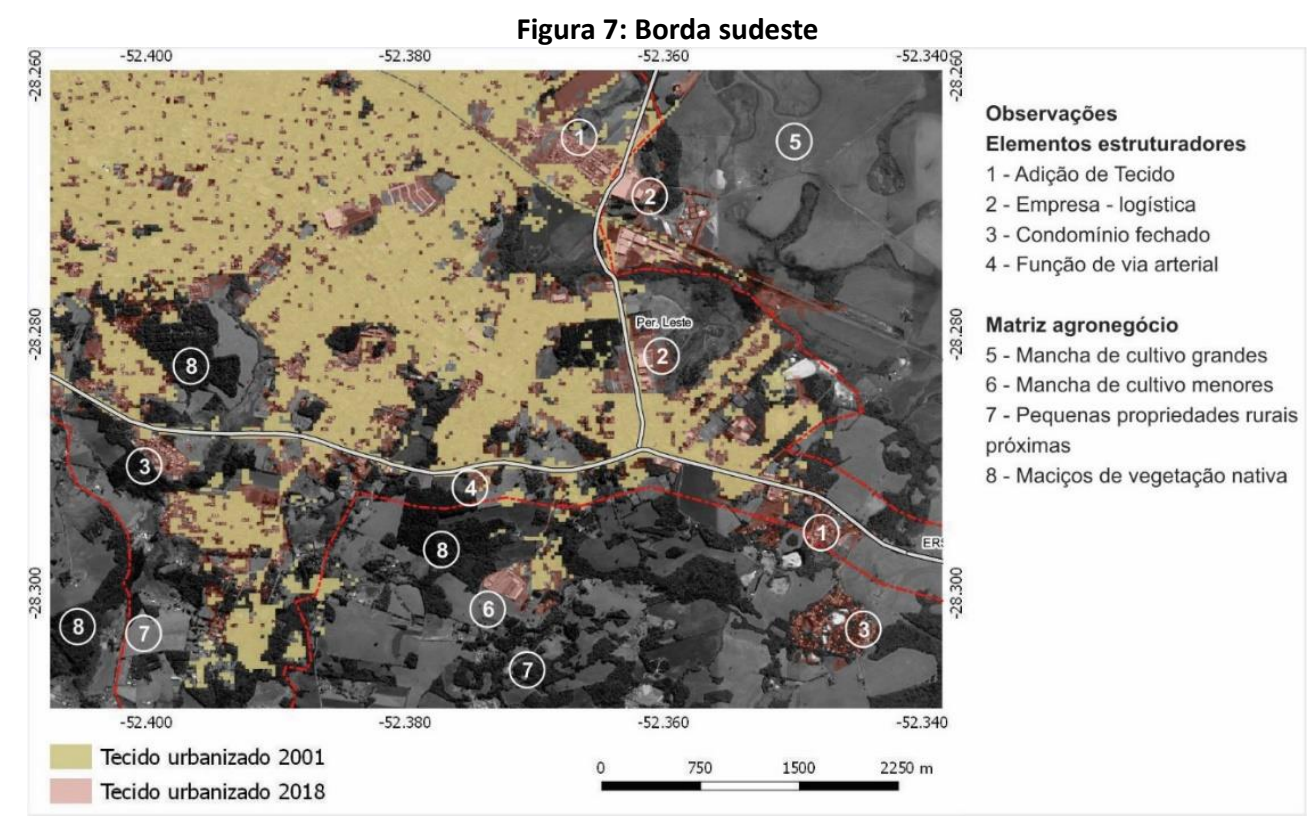

Fonte: autor, 2019.

O quadrante sudoeste pode ser observado na Figura 8. As relações entre os elementos estruturadores e a borda apresentam os seguintes efeitos: o tecido foi desenvolvido para camada de baixa renda (1), e estão localizados além da ERS-324, que configura uma secção (3). A BR-153 é a conexão com a BR-386, que se configura com uma importante ligação com a RMPA. No trecho urbano desta via está instalada a maioria das revendas de equipamentos agrícolas (2). Outro fator relevante é a relação do tecido com o relevo, pois o suporte físico apresenta zonas altas que foram urbanizadas e zonas baixas que são húmidas e contam com áreas de vegetação, isso gera diversos fragmentos de tecidos desagregados; uma das consequências é a dependência da ERS-324, a qual assume a função de via arterial, pois auxilia no fluxo interbairros (4). Observase a adição de tecido para a implementação de novos loteamentos e condomínios (5) no bairro Donária voltados aos empreendimentos do Programa Minha Casa Minha Vida (PMCMV).

Quanto à matriz do agronegócio nesta porção da cidade, as manchas de cultivo voltadas ao agronegócio são menores (6), há maciços de vegetação nativa ao longo dos recursos hídricos e nas áreas de maior declividade (7) e presença de propriedades de pequenos agricultores e de chácaras assentadas ao longo dos recursos hídricos (8). Os quadrantes sudeste e sudoeste 
apresentam suportes físicos com limitação ao agronegócio e urbanização, porém, como tratase de zona com preços do solo mais baixo, têm se caracterizado por um vetor de ocupação.

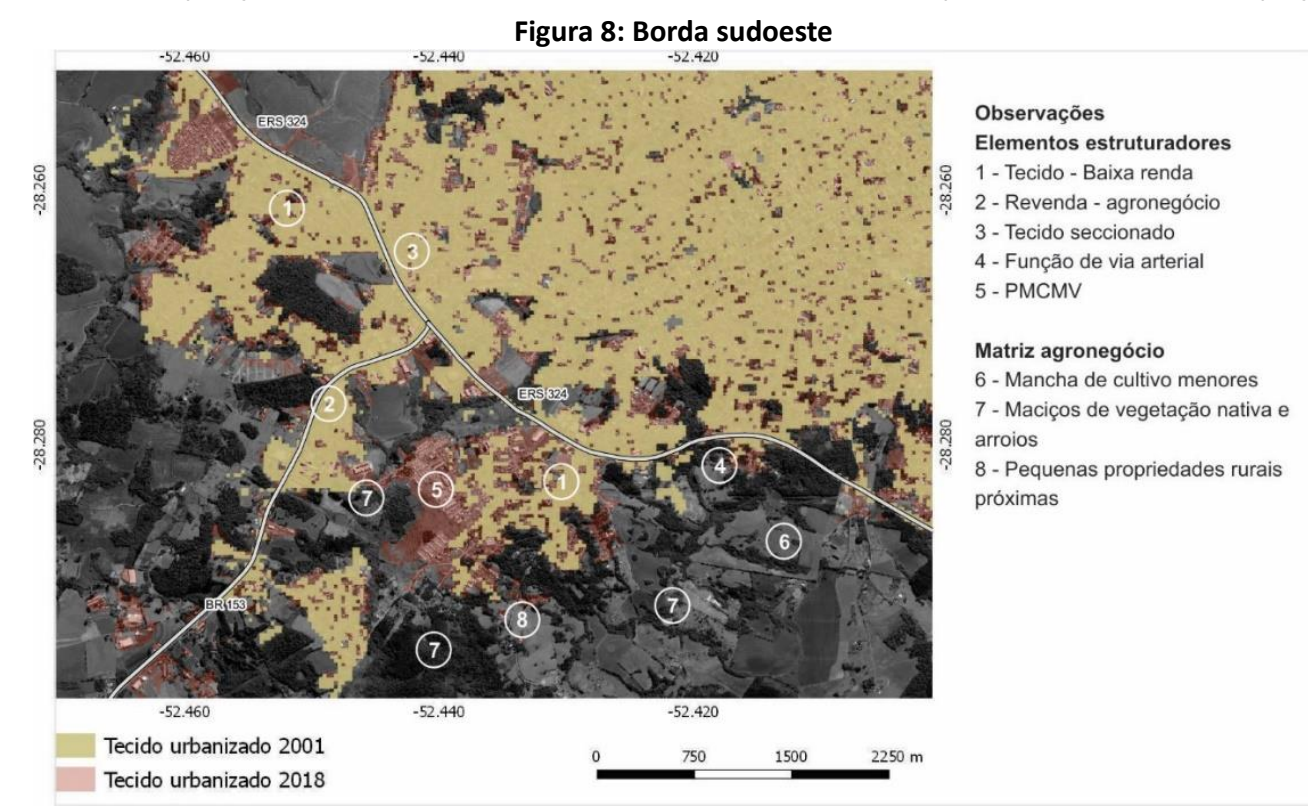

Fonte: autor, 2019.

\section{CONSIDERAÇÕES FINAIS}

A polarização das regiões metropolitanas e dos corredores de desenvolvimento é capaz de gerar oportunidades e crescimentos regionais. Contudo, a região norte do estado não tem estabelecido conexões adequadas. O modal de transporte priorizado historicamente pelo Governo Federal é o rodoviário, e, atualmente, a ligação entre Passo Fundo e a RMPA se dá por rodovias simples e, muitas vezes, com condições de trafegabilidade ruins, uma medida importante para melhorar esta conexão é a duplicação da BR-386 e da BR-285.

Ao analisar o Corede Produção e verificar o contexto regional, é preciso buscar alternativa para mudar a realidade das pequenas cidades, pois a principal atividade econômica está voltada ao agronegócio globalizado. Consequentemente, há baixa diversidade de emprego, produção voltada às commodities, escolaridade baixa, altos índices de empregabilidade voltada ao agronegócio e dependência da monocultura. Um dos efeitos é o incremento da polarização de Passo Fundo para as cidades menores, e a tendência do aumento do desequilíbrio e a desigualdade regional.

$\mathrm{Na}$ escala da borda urbana, os elementos estruturadores têm efeito de via arterial na ligação de tecidos fragmentados, em alguns momentos seccionam o tecido urbano e geralmente são importantes para localização e acessibilidade de empresas. Outro papel é ligar os empreendimentos habitacionais segregados à cidade consolidada, seja a habitação de interesse social, que é implantada longe do centro devido ao preço da terra, seja o condomínio fechado, que utiliza as rodovias para o deslocamento à cidade. É possível observar que a BR-285 


\section{Revista Nacional de}

Gerenciamento de Cidades

concentra a maior parte das empresas, e o trecho urbano da BR-153 também demonstra ser uma via importante pela localização de concessionárias de maquinário agrícola.

A matriz tem efeito na borda urbana, na localização dos equipamentos voltados para o recebimento e a armazenagem de grãos, que estão implantados no limite entre as áreas de cultivo e a cidade, pois necessitam de serviços, recursos financeiros, aportes jurídicos, insumos, máquinas, assistência técnica, etc. Para o encaminhamento da produção até o porto, os elementos estruturadores são de suma importância.

Quanto à dimensão da mancha das áreas de cultivo, o suporte físico tem um papel determinante. Por um lado, os quadrantes nordeste e noroeste se caracterizam por ondulações leves e recursos hídricos mais espaçados, por consequência, são áreas mais amplas para o cultivo de grãos. Por outro lado, os quadrantes sudeste e sudoeste da cidade se configuram com a presença de arroios e afluentes, além de declividades mais elevadas, consequentemente resultam em porções menores para o cultivo de grãos e áreas maiores de mata nativa.

Este trabalho busca contribuir com a discussões acerca do planejamento regional e, assim, proporcionar dados às pessoas que residem na região e aos planejadores, para que possam desenvolver estratégias e táticas para a ocupação mais eficiente do território.

\section{REFERENCIAL BIBLIOGRÁFICO}

AMORIM FILHO, O. B.; SERRA, R. V. Evolução e perspectivas do papel das Cidades Médias no planejamento urbano e regional. In: T. A. Andrade; R. V. Serra (Eds.); Cidades Médias Brasileiras. 2001, Rio de Janeiro: IPEA.

CASIMIRO, P. C. Estrutura, composição e configuração da paisagem: conceitos e princípios para a sua quantificação no âmbito da ecologia da paisagem. Revista Portuguesa de Estudos Regionais, v. 20, p. 75-99, 2009.

DINIZ, C. C. Dinâmica regional e ordenamento do território brasileiro: desafios e oportunidades. Revista Catarinense de Economia, v. 1, n. 1, p. 27, 2017.

ELIAS, D.; PEQUENO, R. Desigualdades socioespaciais nas cidades do agronegócio. Revista Brasileira de Estudos Urbanos e Regionais, v. 9, n. 1, p. 25, 2007.

FINAMORE, E. B. (ED.). Planejamento estratégico da região da produção: do diagnóstico ao mapa estratégico 2008/2028. Passo Fundo: Editora UPF, 2010.

FORMAN, R. T. T. Some general principles of landscape and regional ecology. Landscape Ecology, v. 10, n. 3, p. 133142, 1995.

IBGE. Regiões de Influência das Cidades. Rio de Janeiro: IBGE, 2008.

IOSSIFOVA, D. Searching for common ground: Urban borderlands in a world of borders and boundaries. Cities, v. 34, p. 1-5, 2013.

MADUREIRA, E. M. P. Desenvolvimento regional: principais teorias. Revista Thêma et Scientia, v. 5, n. 2, p. $16,2015$.

MANETTI, C. Um "olhar"sobre o território: análise territorial e estudo prospectivo sobre a "Grande Diagonal Paulista,” 2013. Programa de Pós-Graduação em Gestão Urbana. Pontíficia Universidade Católica de Campinas. Campinas, 2013. 
